OPEN ACCESS

Edited by:

Pia Giovannelli,

University of Campania Luigi Vanvitelli,

Italy

Reviewed by:

Mauricio Rodriguez-Dorantes, Instituto Nacional de Medicina Genómica (INMEGEN), Mexico

Ceshi Chen

Kunming Institute of Zoology, China Savitha Rajarajan,

St. John's Research Institute, India

Lei Shi,

Tianjin Medical University, China

${ }^{*}$ Correspondence:

Xiaoyun Mao

xymao@cmu.edu.cn

Specialty section: This article was submitted to Cancer Endocrinology, a section of the journal

Frontiers in Endocrinology

Received: 29 March 2021 Accepted: 12 October 2021 Published: 03 November 2021

Citation:

Zhang A, Wang X, Fan $C$ and Mao X (2021) The Role of Ki67 in Evaluating

Neoadjuvant Endocrine Therapy of Hormone Receptor-Positive Breast Cancer.

Front. Endocrinol. 12:687244. doi: 10.3389/fendo.2021.687244

\section{The Role of Ki67 in Evaluating Neoadjuvant Endocrine Therapy of Hormone Receptor-Positive Breast Cancer}

\author{
Ailin Zhang ${ }^{1}$, Xiaojing Wang $^{2}$, Chuifeng Fan ${ }^{2}$ and Xiaoyun Mao ${ }^{1 *}$ \\ ${ }^{1}$ Department of Breast Surgery, The First Affiliated Hospital of China Medical University, Shenyang, China, ${ }^{2}$ Department of \\ Pathology, First Affiliated Hospital and College of Basic Medical Sciences of China Medical University, Shenyang, China
}

Ki67 is a proliferation marker. It has been proposed as a useful clinical marker for breast cancer subtype classification, prognosis, and prediction of therapeutic response. But the questionable analytical validity of Ki67 prevents its widespread adoption of these measures for treatment decisions in breast cancer. Currently, Ki67 has been tested as a predictive marker for chemotherapy using clinical and pathological response as endpoints in neoadjuvant endocrine therapy. Ki67 can be used as a predictor to evaluate the recurrence-free survival rate of patients, or its change can be used to predict the preoperative "window of opportunity" in neoadjuvant endocrine therapy. In this review, we will elaborate on the role of Ki67 in neoadjuvant endocrine therapy in breast cancer.

Keywords: neoadjuvant endocrine therapy, breast cancer, Ki67, hormone-positive breast cancer, clinical marker

\section{INTRODUCTION}

Ki67 is a nuclear antigen that is an excellent marker of active cell proliferation in the normal and tumor cell populations (1). It has been proposed as a useful clinical marker for breast cancer subtype classification, prognosis, and prediction of therapeutic response (2-4). But the questionable analytical validity of Ki67 prevents its widespread adoption of these measures for treatment decisions in breast cancer (5). Previous study suggested that baseline Ki67 and its change after short-term endocrine treatment (e.g., 2 weeks) have predictive value of recurrence-free survival (6). Currently, several studies have investigated the possible use of Ki67 assessment in neoadjuvant endocrine therapy (NET). This review assessed the role of Ki67 in NET of breast cancer.

\section{KI67 STRUCTURE AND BIOLOGICAL FUNCTION}

Ki67 is expressed in all active phases of the cell cycle (late G1 phase and subsequent S, G2, and M phases), peaks in $M$ phase, dissipates rapidly after mitosis, and is not expressed in stationary G0 phase (7). It is encoded by MKI67 and maps to human 10q26.2. It has a potential phosphorylation site for a range of essential kinases, PEST $^{1}$ sequences, and a forkhead-associated domain (8) (Figure 1). It acts as an early protein to bind the perichromosomal layer in mitosis at the transition

\footnotetext{
${ }^{1}$ PEST: The amino acid sequences of ten proteins with intracellular halflives less than 2 hours contain one or more regions rich in proline $(\mathrm{P})$, glutamicacid $(\mathrm{E})$, serine $(\mathrm{S})$, and threonine $(\mathrm{T})$.
} 
from prophase to prometaphase (9). During mitosis, Ki67 stabilizes and maintains the mitotic spindle and prevents chromosomes from collapsing into a single chromatin mass after nuclear envelope disassembly, thus enabling independent chromosome motility and efficient interactions with the mitotic spindle $(10,11)$. The tandem repeat group of Ki67 contains residues of Cyclin dependent kinase 1 (CDK1) phosphorylation during mitosis $(12,13)$, and many biological functions of Ki67 have subsequently been shown to be related to phosphorylation (8).

\section{KI67 IN BREAST CANCER}

Ki67 is a marker of cell proliferation. In normal healthy breast tissue, very low levels of $\operatorname{Ki67}(<3 \%)$ have been reported $(14,15)$. Previous research indicated that estrogen receptor (ER)-positive cells did not proliferate in rodent mammary gland; $\mathrm{ER} \alpha$ receives the proliferation signal from E2, initiates DNA synthesis, and is then lost from cells (16). The subsequent steps in proliferation can proceed in the absence of either $\operatorname{ER} \alpha$ or $\operatorname{ER} \beta$ (16). Ki67 is expressed exclusively in ER-negative cells in normal breast tissue $(15,17,18)$. Ki67 expression is significantly higher in hyperplastic enlarged lobular units than in adjacent normal terminal duct lobular units (average 6.3\% vs. $2.0 \%$; $\mathrm{P}<0.0001$ ) (19) and is related to the subsequent risk of breast cancer $(14,20$, 21). The exclusive Ki67 expression pattern with ER is disrupted during breast carcinogenesis $(22,23)$. Numerous studies have indicated that early-stage breast cancer patients with high Ki67 expression have a higher risk of recurrence and poorer survival rate (3, 24-27). The International Ki67 in Breast Cancer Working Group (IKWG) accepted that Ki67 immunohistochemistry (IHC) as a prognostic marker in breast cancer has limited clinical validity at present. Ki67 IHC is used as a prognostic marker in early breast cancer regarding whether further adjuvant chemotherapy is warranted to predict or monitor chemotherapy response (28). Ki67 IHC is a useful tool in assessing the risk of recurrence for ER-positive human epidermal growth factor receptor 2 (HER2)-negative breast cancers, where it may be considered a surrogate of molecular assays for distinguishing luminal A from luminal B breast cancer subtypes. High Ki67 has been reported to be associated with a good clinical response to chemotherapy (3), especially in triple- negative breast cancer $(15,29)$. But it had limited independent significance and does not merit measurements in most routine clinical scenarios. A clinical trial from the European Institute of Oncology indicated that high Ki67 ( $\geq 32 \%)$ can benefit from adjuvant chemotherapy in luminal B breast cancer with positive lymph node metastasis (30). Penault-Llorca et al. (31) reported that a high Ki67 index $(\geq 20 \%)$ in the PACS01 trial was linked with a higher efficacy of docetaxel in adjuvant therapy for ERpositive breast cancer. The BCIRG001 clinical trial found that docetaxel, doxorubicin, and cyclophosphamide (TAC) chemotherapy regimen had a significant complementary effect on endocrine therapy for patients with a high Ki67 index $(\geq 13 \%)$, ER positivity, and lymph node positivity (32). In IBCSG trials VIII and IX, high Ki67 index $(\geq 19 \%)$ correlated with poor disease-free survival among 1,521 patients with endocrine-reactive breast cancer (33). Ki67 index is a valuable prognostic indicator in endocrine-responsive breast cancer without lymph node metastasis, but it is not a predictive factor of better response to adjuvant chemotherapy in these studies $(30,34)$.

\section{KI67 IN NEOADJUVANT ENDOCRINE THERAPY}

The efficacy evaluation of neoadjuvant chemotherapy (NAC) is mainly based on the clinical response and pathologic response tumor and lymph nodes after treatment (35). In NET, Ki67 has been tested as a predictive marker for chemotherapy using clinical and pathological responses as endpoints (36). Several large clinical trials of NET have assessed the change of Ki67 as an endpoint (37-39) (Table 1). Two important clinical trials of NETs, the Immediate Preoperative Anastrozole, Tamoxifen, or Combined with Tamoxifen (IMPACT) trial and P024, established Ki67 as the evaluation index of NETs. IMPACT compared the efficacy of NET with anastrozole, tamoxifen, and a combination of anastrozole and tamoxifen in postmenopausal women with ER-positive invasive primary breast cancer (45). P024 compared letrozole with tamoxifen in NET $(40,46)$ IMPACT is a clinical trial similar to the ATAC (Arimidex, Tamoxifen, Alone or in Combination) trial, which compared 5 years of the aromatase inhibitor anastrozole alone, tamoxifen

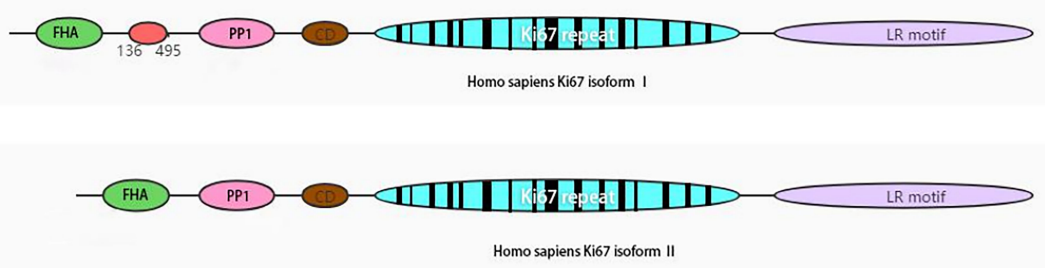

FIGURE 1 | Schematic view of human Ki67 protein structure. The isoform II lacks amino acid 136-495. FHA, forkhead-associated domain; PP1, PP1-binding domain; CD, conserved domain; LR, leucine-arginine-rich domain. 
TABLE 1 | Main neoadjuvant endocrine trials.

\begin{tabular}{|c|c|c|}
\hline $\begin{array}{l}\text { Clinical } \\
\text { trials }\end{array}$ & Clinical response & Ki67 outcome \\
\hline $\begin{array}{l}\text { P024 (40- } \\
42)\end{array}$ & $\begin{array}{l}\text { ORR letrozole 55\% vs. tamoxifen 36\% }(P<0.001) \text {; ultrasound response } \\
\text { letrozole } 35 \% \text { vs. tamoxifen } 25 \%(P<0.05) \text {; mammographic response } \\
\text { letrozole } 34 \% \text { vs. tamoxifen } 16 \%(P<0.001) \text {; breast-conserving surgery } \\
\text { letrozole } 45 \% \text { vs. tamoxifen } 35 \%(P=0.022) \text {. }\end{array}$ & $\begin{array}{l}\text { No interaction with treatment-induced changes in Ki67 or absolute } \\
\text { posttreatment Ki67 levels in either tamoxifen- or letrozole-treated tumor } \\
\text { samples. Letrozole inhibited Ki67 to a greater extent than tamoxifen did (Ki67 } \\
\text { geometric mean reduction } 87 \% \text { vs. } 75 \% \text {, respectively; P = 0.0009). }\end{array}$ \\
\hline $\begin{array}{l}\text { IMPACT } \\
\text { (39) }\end{array}$ & $\begin{array}{l}\text { There were no significant differences in OR in anastrozole, tamoxifen, or } \\
\text { combination. }\end{array}$ & $\begin{array}{l}\text { Greater Ki67 reduction in anastrozole arm. Ki67 geometric mean reduction: } \\
\text { anastrozole } 76 \% \text { at } 2 \text { weeks/ } 82 \% \text { at } 12 \text { weeks; tamoxifen } 59 \% \text { at } 2 \text { weeks/ } \\
62 \% \text { at } 12 \text { weeks; combination } 64 \% \text { at } 2 \text { weeks } 61 \% \text { at } 12 \text { weeks. }\end{array}$ \\
\hline $\begin{array}{l}\text { ACOSOG } \\
\text { Z1031 } \\
(43)\end{array}$ & CRR letrozole $75 \%$ vs. exemestane $63 \%$ vs. anastrozole $69 \%$. & $\begin{array}{l}\text { No significance difference in Ki67 geometric mean reduction. Anastrozole } 79 \% \\
\text { vs. exemestane } 79 \% \text { vs. letrozole } 82 \% \text {. Ki67-based data are closely equivalent } \\
\text { with the data in adjuvant endocrine trials, therefore predicting similar activity as } \\
\text { adjuvant therapies. }\end{array}$ \\
\hline $\begin{array}{l}\text { PROACT } \\
(44)\end{array}$ & $\begin{array}{l}\text { In hormonal therapy-only patients, ORR favored anastrozole arm } \\
\text { (anastrozole } 33 \% \text { vs. tamoxifen } 27 \%, P=0.04 \text { ), feasible surgery at } \\
\text { baseline improved after } 3 \text { months in } 43 \% \text { of patients receiving anastrozole } \\
\text { and } 31 \% \text { receiving tamoxifen ( } P=0.04 \text { ). }\end{array}$ & No data about Ki67 \\
\hline
\end{tabular}

ORR, overall response rate; $C R R$, complete response rate.

alone, and their combination as adjuvant therapy in postmenopausal women with localized breast cancer. IMPACT was designed to test the hypothesis that the clinical response or the change in Ki67 predicts the outcome of ATAC (39). The ATAC trial is the largest adjuvant trial with the longest follow-up data to date, with 24,522 woman-years of follow-up in the anastrozole group and 23,950 woman-years in the tamoxifen group $(47,48)$. The results of this study are valuable, and its data continue to demonstrate improved efficacy for 5 years of anastrozole over tamoxifen alone. IMPACT has a similar design to ATAC in NET, avoiding a large number of patients and long follow-up time required for the efficacy evaluation of adjuvant trials, and aims to compare the recurrence and death risk of hormone receptor-positive patients in three NET regimens. The IMPACT trial required only 330 patients and a follow-up of just 3 months to provide its primary endpoint (40). In IMPACT, the change of Ki67 was greater in the anastrozole group than in the other groups at 2 weeks and 12 weeks, which closely parallels the results of the relative recurrence-free survival with adjuvant endocrine therapy after long follow-up in the ATAC trial in 9,366 patients. The short-term changes in Ki67, not the clinical evaluation (tumor size) in NET, might predict the long-term outcome during adjuvant use of the same treatments.

P024 was a randomized, multinational, double-blind study comparing 4 months of letrozole vs. tamoxifen in postmenopausal women with hormone-responsive primary untreated breast cancer (41). P024 indicated that the percentage of Ki67-positive cells, pathological tumor size, lymph node status, and ER status were independently associated with breast cancer-specific survival and relapse-free survival. Based on these factors, Ellis et al. (46) obtained a clinically valuable prognostic model of preoperative endocrine prognostic index (PEPI) score for the outcome prediction of hormone-positive breast cancer with NET. The Ki67 and PEPI triage approaches can predict the risk of relapse. NET was initially an option for breast cancer patients who were too frail to have surgery or cytotoxic chemotherapy. It is very difficult to evaluate the efficacy of adjuvant endocrine therapy because of its long-term follow-up, and NET offers useful clues. The initial endocrine neoadjuvant therapy clinical trial collected data to evaluate the long-term outcome of adjuvant endocrine therapy indirectly rather than as a neoadjuvant treatment (49-51). Future adjuvant endocrine therapy clinical research designs should be based on a biological superiority hypothesis generated by a neoadjuvant endocrine study (52).

After almost 20 years of clinical studies on NETs, with considerable response rates in HR-positive breast cancer, NETs could be a significantly less toxic alternative to NAC for a subgroup of endocrine therapy-responsive breast cancer. The Z1031A trial enrolled postmenopausal women with large (stage II/III) ER-positive breast cancer with random anastrozole, exemestane, or letrozole NET. Subsequently, in Z1031B, the trial protocol was amended to include Ki67 determination after 2-4 weeks of neoadjuvant aromatase inhibitor therapy (53). If Ki67 was $>10 \%$, patients were switched to neoadjuvant chemotherapy on the basis of a presumptive lack of hormonal therapy benefit. A pathologic complete response ( $\mathrm{pCR}$ ) rate of $>20 \%$ was the predefined efficacy threshold. With $>5$ years of median follow-up, only $3.7 \%$ (4/109) with a PEPI score of 0 relapsed vs. $14.4 \%$ (49/341) with a PEPI score $>0$. The Ki67 and PEPI algorithms can be used to evaluate relapse risk after NET. Miller et al. (54) collected 63 postmenopausal breast cancer patients with neoadjuvant letrozole for 3 months. Reduction in Ki67 $>40 \%$ between pretreatment and 10-14 days was related to pathological responses. A pooled analysis of two multicenter, randomized, noncomparative, phase 2 clinical trials (HORGEN and CARMINA02) evaluating neoadjuvant anastrozole and fulvestrant efficacy for postmenopausal HR+/HER2- breast cancer indicated that PEPI can identify a subset of patients with poorer prognosis who should be offered all appropriate adjuvant therapy (55). Ki67 in neoadjuvant trials predicted the long-term outcomes of large adjuvant trials; Ki67 and PEPI can be predictors for evaluating the recurrence-free survival of breast cancer patients with NET (50). Early breast cancer patients with a PEPI $=0$ have little to gain from adding additional adjuvant systemic therapy to their endocrine therapy (46). 
The postmenopausal women with hormone-sensitive early breast cancer (POETIC) study was a phase 3 trial in which postmenopausal hormone receptor-positive early breast cancer patients were randomly assigned to POAI (letrozole or anastrozole) for 14 days before and following surgery or no POAI (control) (38). The data from POETIC showed that the patients with a low baseline Ki67 $(<10 \%)$ had a low risk of recurrence $(4.3 \%$ in HER-2-negative breast cancer, $10.1 \%$ in HER-2-positive breast cancer), and those with a high baseline Ki67 ( $\geq 10 \%)$ with conversion to low Ki67 after 2 weeks of NET had a high recurrence $(21.5 \%$ in HER-2-negative breast cancer, $15.7 \%$ in HER-2-positive breast cancer). In patients with low baseline Ki67 or POAI-induced low Ki67 associated with good prognosis, adjuvant standard endocrine therapy and high POAIinduced Ki67 might benefit from further adjuvant treatment or trials of new therapies. The Ki67 change after 2 weeks of NET provided substantially more prognostic information for those who had high baseline Ki67.

Clinical practice is unequal to clinical trials, and every patient is unique. In our clinical practice, some patients need time to accept their disease and the subsequent treatment. Perhaps it is just a temporary choice for some ER-positive HER-2-negative breast cancer patients who refuse chemotherapy because of its side effects. The NET, Ki67, and PEPI systems are useful tools that provide useful information about screening for de-escalation treatment in low-risk patients. Especially in times of crisis, such as during the coronavirus disease 2019 (COVID-19) pandemic, it is of paramount importance for most patients to reduce or postpone visits to the hospital $(56,57)$. The NET, Ki67, and PEPI systems are alternative choices for ER-positive HER-2negative breast cancer. However, $5 \%-20 \%$ of ER-positive HER2-negative breast cancers have clinical progression (58). As we know, the data about axillary lymph nodes after NET remain limited; no research majored on the relationship between the Ki67 index and axillary lymph node response to NET. A previous study indicated that NETs can have equivalent clinical benefit to neoadjuvant chemotherapy in appropriately selected patients (59). According to the subtype of breast cancer, the attitudes of the patients and family members, and the information provided by clinical trials, the determination of NET should be cautious and followed up closely. For patients who demonstrate early endocrine resistance to NETs, additional adjuvant systemic therapy should consider alternative treatment approaches to reduce recurrence risk and aggression.

\section{KI67 MEASUREMENT IN NEOADJUVANT ENDOCRINE THERAPY}

Ki67 measures the proportion of proliferating cells in breast cancer. Ki67 IHC has been used for many years and is reported by pathologists as a Ki67 index in the clinic. However, Ki67 is not completely integrated in clinical decision-making because of a lack of a standardized procedure for Ki67 assessment as well as persistence of several issues of debate with regard to the Ki67 assay interpretation and the marker's clinical utility. With the goal of establishing a uniform Ki67 evaluation system, the International
Ki67 in Breast Cancer Working Group of the Breast International Group and North American Breast Cancer Group conducted a Ki67 reproducibility study. They found that tumor region selection, hot spot analysis, counting method, and subjective assessment of staining positivity resulted in interlaboratory discordance (60-62). A set of guidelines for staining, analysis, and reporting of $\mathrm{Ki} 67$ is recommended by the IKWG $(5,28)$.

The cutoff for Ki67 is still under debate. Published Ki-67 data from the IMPACT and P024 were used for the development of cutoff points for prospective validation. In the IMPACT trial, the geometric mean percentage change of Ki67 after 2 and 12 weeks of NTS was greater in the anastrozole group (76.0\% and $81.6 \%$ ) than in the tamoxifen group $(59.5 .0 \%$ and $61.9 \%)$ or the combination group (63.9\% and 61.1\%) (47). In P024, letrozole inhibited Ki67 to a greater extent than tamoxifen did (reduction in geometric mean Ki67 level $87 \%$ vs. $75 \%$, respectively; $P=$ $0.0009)(42,46)$. The PEPI score was established in the P024 trial and validated in IMPACT trial $(46,63)$. It combines the residual Ki67 score, which was analyzed as the natural log interval, or per 2.7-fold increase according to the original scale of percentage values $(53,63)$. The Z1031 study established a Ki67 cutoff point for triage to chemotherapy after 2 weeks of AI therapy (56). If Ki67 $\leq 10 \%$, the patient continued AI therapy for another 12-14 weeks and then proceeded to surgery. If the Ki67 level was $>10 \%$, the patients were offered either neoadjuvant chemotherapy or surgery. In HORGEN and CARMINA02, the cutoff of Ki67 expression is $\leq 10 \%$ vs. $>10 \%$ (55). In the POETIC clinical trial, the cutoff was $<10 \%$ vs. $\geq 10 \%$ (28). The change in Ki67 is of predictive value in $\operatorname{NET}(28,38)$. Currently, the evaluation of Ki67 is considered important in clinical practice, especially in neoadjuvant endocrine clinical trials, and standardized and accurate evaluation under strict quality control is needed. Unless the assessment is carried out in an experienced laboratory with its own reference data and strict quality control, it is not reliable to directly apply a specific cutoff value to make decisions.

\section{CONCLUSION}

Ki67 is a useful proliferation marker; its potential usefulness in predicting response and long-term outcome is explored in NET. It cannot represent or predict the regression of the primary tumor or lymph node after NET. It can be used as a predictor to evaluate the recurrence-free survival rate of patients, or its change can be used as the preoperative "window of opportunity" in NET. At present, a set of guidelines for staining, analysis, and reporting of Ki67 is recommended in breast cancer, but the uniformity among different centers needs to be improved. Standardized NET, Ki67, and PEPI systems require further standardization and subsequent clinical validation.

In clinical practice, the aim of neoadjuvant therapy is to shrink or downstage breast cancer, increase the breast conservation rate, and help to screen appropriate patients for de-escalation or escalation therapy, regardless of neoadjuvant chemotherapy or NET. For triple-negative and HER-2-positive breast cancer, neoadjuvant chemotherapy is the first choice. 
For ER-positive and HER-2-negative breast cancer, is NAC or NET the best choice or first choice? With large tumor burden, should NAC or NET be selected? With lymph node metastasis, should NAC or NET be selected? Ki67 may offer clues. Previous reports indicated that a higher pretreatment Ki67 was more likely to attain pCR after NAC and can be used as a predictor of NAC in luminal subtypes only $(3,4,64)$. This suggests that higher pretreatment Ki67 may improve the prognostic significance of clinical response in NAC. Due to the uniformly low pCR and slow response $(65,66)$, NETs are not the first choice for the quick downstaging of large tumor burden. Due to the limited data on axillary management or outcomes in NET clinical trials, most patients selected for NETs have limited nodal burden. More research is needed.

\section{REFERENCES}

1. Schlüter C, Duchrow M, Wohlenberg C, Becker MH, Key G, Flad HD, et al. The Cell Proliferation-Associated Antigen of Antibody Ki-67: A Very Large, Ubiquitous Nuclear Protein With Numerous Repeated Elements, Representing a New Kind of Cell Cycle-Maintaining Proteins. J Cell Biol (1993) 123:513-22. doi: 10.1083/jcb.123.3.513

2. Healey MA, Hirko KA, Beck AH, Collins LC, Schnitt SJ, Eliassen AH, et al. Assessment of Ki67 Expression for Breast Cancer Subtype Classification and Prognosis in the Nurses' Health Study. Breast Cancer Res Treat (2017) 166:613-22. doi: 10.1007/s10549-017-4421-3

3. Urruticoechea A, Smith IE, Dowsett M. Proliferation Marker Ki-67 in Early Breast Cancer. J Clin Oncol (2005) 23:7212-20. doi: 10.1200/JCO.2005.07.501

4. Faneyte IF, Schrama JG, Peterse JL, Remijnse PL, Rodenhuis S, van de Vijver MJ. Breast Cancer Response to Neoadjuvant Chemotherapy: Predictive Markers and Relation With Outcome. Br J Cancer (2003) 88:406-12. doi: 10.1038/sj.bjc.6600749

5. Dowsett M, Nielsen TO, A'Hern R, Bartlett J, Coombes RC, Cuzick J, et al. Assessment of Ki67 in Breast Cancer: Recommendations From the International Ki67 in Breast Cancer Working Group. J Natl Cancer Inst (2011) 103:1656-64. doi: 10.1093/jnci/djr393

6. Dowsett M, Smith IE, Ebbs SR, Dixon JM, Skene A, A'Hern R, et al. Prognostic Value of Ki67 Expression After Short-Term Presurgical Endocrine Therapy for Primary Breast Cancer. J Natl Cancer Inst (2007) 99:167-70. doi: 10.1093/jnci/djk020

7. Gerdes J, Lemke H, Baisch H, Wacker HH, Schwab U, Stein H, et al. Cell Cycle Analysis of a Cell Proliferation-Associated Human Nuclear Antigen Defined by the Monoclonal Antibody Ki-67. J Immunol (Baltimore Md 1950) (1984) 133:1710-5

8. Endl E, Gerdes J. The Ki-67 Protein: Fascinating Forms and an Unknown Function. Exp Cell Res (2000) 257:231-7. doi: 10.1006/excr.2000.4888

9. Juríková M, Danihel Ľ., Polák Š., Varga I. Ki67, PCNA, and MCM Proteins: Markers of Proliferation in the Diagnosis of Breast Cancer. Acta Histochem (2016) 118:544-52. doi: 10.1016/j.acthis.2016.05.002

10. Vanneste D, Takagi M, Imamoto N, Vernos I. The Role of Hklp2 in the Stabilization and Maintenance of Spindle Bipolarity. Curr Biol CB (2009) 19:1712-7. doi: 10.1016/j.cub.2009.09.019

11. Cuylen S, Blaukopf C, Politi AZ, Müller-Reichert T, Neumann B, Poser I, et al. Ki-67 Acts as a Biological Surfactant to Disperse Mitotic Chromosomes. Nature (2016) 535:308-12. doi: 10.1038/nature 18610

12. Scholzen T, Gerdes J. The Ki-67 Protein: From the Known and the Unknown. J Cell Physiol (2000) 182:311-22. doi: 10.1002/(SICI)1097-4652(200003) 182:3<311::AID-JCP1>3.0.CO;2-9

13. Takagi M, Nishiyama Y, Taguchi A, Imamoto N. Ki67 Antigen Contributes to the Timely Accumulation of Protein Phosphatase $1 \gamma$ on Anaphase Chromosomes. J Biol Chem (2014) 289:22877-87. doi: 10.1074/jbc.M114.556647

14. Huh SJ, Oh H, Peterson MA, Almendro V, Hu R, Bowden M, et al. The Proliferative Activity of Mammary Epithelial Cells in Normal Tissue Predicts

\section{AUTHOR CONTRIBUTIONS}

All authors made substantial contributions to articles reviewed in this manuscript, were involved in the drafting and revision, and approved the final version of this manuscript.

\section{FUNDING}

This work was supported by the National Natural Science Foundation of China (No. 81972791). The funders had no role in study design, data collection and analysis, decision to publish, or preparation of the article.

Breast Cancer Risk in Premenopausal Women. Cancer Res (2016) 76:1926-34. doi: 10.1158/0008-5472.CAN-15-1927

15. Yerushalmi R, Woods R, Ravdin PM, Hayes MM, Gelmon KA. Ki67 in Breast Cancer: Prognostic and Predictive Potential. Lancet Oncol (2010) 11:174-83. doi: 10.1016/S1470-2045(09)70262-1

16. Saji S, Jensen EV, Nilsson S, Rylander T, Warner M, Gustafsson JA. Estrogen Receptors Alpha and Beta in the Rodent Mammary Gland. Proc Natl Acad Sci USA (2000) 97:337-42. doi: 10.1073/pnas.97.1.337

17. Krishnamurthy S, Sneige N. Molecular and Biologic Markers of Premalignant Lesions of Human Breast. Adv anatomic Pathol (2002) 9:185-97. doi: 10.1097/ 00125480-200205000-00002

18. Kontzoglou K, Palla V, Karaolanis G, Karaiskos I, Alexiou I, Pateras I, et al. Correlation Between Ki67 and Breast Cancer Prognosis. Oncology (2013) 84:219-25. doi: 10.1159/000346475

19. Lee S, Mohsin SK, Mao S, Hilsenbeck SG, Medina D, Allred DC. Hormones, Receptors, and Growth in Hyperplastic Enlarged Lobular Units: Early Potential Precursors of Breast Cancer. Breast Cancer Res BCR (2006) 8:R6. doi: $10.1186 /$ bcr 1367

20. Santisteban M, Reynolds C, Barr Fritcher EG, Frost MH, Vierkant RA Anderson SS, et al. Ki67: A Time-Varying Biomarker of Risk of Breast Cancer in Atypical Hyperplasia. Breast Cancer Res Treat (2010) 121:431-7. doi: 10.1007/s10549-009-0534-7

21. Oh H, Eliassen AH, Wang M, Smith-Warner SA, Beck AH, Schnitt SJ, et al. Expression of Estrogen Receptor, Progesterone Receptor, and Ki67 in Normal Breast Tissue in Relation to Subsequent Risk of Breast Cancer. NPJ Breast Cancer (2016) 2:16032-. doi: 10.1038/npjbcancer.2016.32

22. Clarke RB. Steroid Receptors and Proliferation in the Human Breast. Steroids (2003) 68:789-94. doi: 10.1016/S0039-128X(03)00122-3

23. Ricketts D, Turnbull L, Ryall G, Bakhshi R, Rawson NS, Gazet JC, et al. Estrogen and Progesterone Receptors in the Normal Female Breast. Cancer Res (1991) 51:1817-22.

24. de Azambuja E, Cardoso F, de Castro G Jr, Colozza M, Mano MS, Durbecq V, et al. Ki-67 as Prognostic Marker in Early Breast Cancer: A Meta-Analysis of Published Studies Involving 12,155 Patients. Br J Cancer (2007) 96:1504-13. doi: $10.1038 /$ sj.bjc. 6603756

25. Stuart-Harris R, Caldas C, Pinder SE, Pharoah P. Proliferation Markers and Survival in Early Breast Cancer: A Systematic Review and Meta-Analysis of 85 Studies in 32,825 Patients. Breast (Edinburgh Scotland) (2008) 17:323-34. doi: 10.1016/j.breast.2008.02.002

26. Sheri A, Dowsett M. Developments in Ki67 and Other Biomarkers for Treatment Decision Making in Breast Cancer. Ann Oncol Off J Eur Soc Med Oncol (2012) 23 Suppl 10:x219-227. doi: 10.1093/annonc/mds307

27. Liang Q, Ma D, Gao RF, Yu KD. Effect of Ki-67 Expression Levels and Histological Grade on Breast Cancer Early Relapse in Patients With Different Immunohistochemical-Based Subtypes. Sci Rep (2020) 10:7648. doi: 10.1038/ s41598-020-64523-1

28. Nielsen TO, Leung SCY, Rimm DL, Dodson A, Acs B, Badve S, et al. Assessment of Ki67 in Breast Cancer: Updated Recommendations From the 
International Ki67 in Breast Cancer Working Group. J Natl Cancer Inst (2021) 113(7):808-19. doi: 10.1093/jnci/djaa201.

29. Zhu X, Chen L, Huang B, Wang Y, Ji L, Wu J, et al. The Prognostic and Predictive Potential of Ki-67 in Triple-Negative Breast Cancer. Sci Rep (2020) 10:225. doi: 10.1038/s41598-019-57094-3

30. Criscitiello C, Disalvatore D, De Laurentiis M, Gelao L, Fumagalli L, Locatelli M, et al. High Ki-67 Score is Indicative of a Greater Benefit From Adjuvant Chemotherapy When Added to Endocrine Therapy in Luminal B HER2 Negative and Node-Positive Breast Cancer. Breast (2014) 23:69-75. doi: 10.1016/j.breast.2013.11.007

31. Penault-Llorca F, André F, Sagan C, Lacroix-Triki M, Denoux Y, Verriele V, et al. Ki67 Expression and Docetaxel Efficacy in Patients With Estrogen Receptor-Positive Breast Cancer. J Clin Oncol (2009) 27:2809-15. doi: 10.1200/JCO.2008.18.2808

32. Hugh J, Hanson J, Cheang MC, Nielsen TO, Perou CM, Dumontet C, et al. Breast Cancer Subtypes and Response to Docetaxel in Node-Positive Breast Cancer: Use of an Immunohistochemical Definition in the BCIRG 001 Trial. J Clin Oncol (2009) 27:1168-76. doi: 10.1200/JCO.2008.18.1024

33. Viale G, Regan MM, Mastropasqua MG, Maffini F, Maiorano E, Colleoni M, et al. Predictive Value of Tumor Ki-67 Expression in Two Randomized Trials of Adjuvant Chemoendocrine Therapy for Node-Negative Breast Cancer. J Natl Cancer Inst (2008) 100:207-12. doi: 10.1093/jnci/djm289

34. International Breast Cancer Study (IBCSG), G, Castiglione-Gertsch M, O'Neill A, Price KN, Goldhirsch A, Coates AS, et al. Adjuvant Chemotherapy Followed by Goserelin Versus Either Modality Alone for Premenopausal Lymph Node-Negative Breast Cancer: A Randomized Trial. J Natl Cancer Inst (2003) 95:1833-46. doi: 10.1093/jnci/djg119

35. Wang H, Mao X. Evaluation of the Efficacy of Neoadjuvant Chemotherapy for Breast Cancer. Drug Des Devel Ther (2020) 14:2423-33. doi: 10.2147/ DDDT.S253961

36. Penault-Llorca F, Radosevic-Robin N. Ki67 Assessment in Breast Cancer: An Update. Pathology (2017) 49:166-71. doi: 10.1016/j.pathol.2016.11.006

37. Smith IE, Walsh G, Skene A, Llombart A, Mayordomo JI, Detre S, et al. A Phase II Placebo-Controlled Trial of Neoadjuvant Anastrozole Alone or With Gefitinib in Early Breast Cancer. J Clin Oncol (2007) 25:3816-22. doi: 10.1200/ JCO.2006.09.6578

38. Smith I, Robertson J, Kilburn L, Wilcox M, Evans A, Holcombe C, et al. LongTerm Outcome and Prognostic Value of Ki67 After Perioperative Endocrine Therapy in Postmenopausal Women With Hormone-Sensitive Early Breast Cancer (POETIC): An Open-Label, Multicentre, Parallel-Group, Randomised, Phase 3 Trial. Lancet Oncol (2020) 21:1443-54. doi: 10.1016/S1470-2045(20) 30458-7

39. Smith IE, Dowsett M, Ebbs SR, Dixon JM, Skene A, Blohmer JU, et al. Neoadjuvant Treatment of Postmenopausal Breast Cancer With Anastrozole, Tamoxifen, or Both in Combination: The Immediate Preoperative Anastrozole, Tamoxifen, or Combined With Tamoxifen (IMPACT) Multicenter Double-Blind Randomized Trial. J Clin Oncol (2005) 23:510816. doi: $10.1200 /$ JCO.2005.04.005

40. Ellis MJ, Miller WR, Tao Y, Evans DB, Chaudri Ross HA, Miki Y, et al. Aromatase Expression and Outcomes in the P024 Neoadjuvant Endocrine Therapy Trial. Breast Cancer Res Treat (2009) 116:371-8. doi: 10.1007/ s10549-008-0161-8

41. Eiermann W, Paepke S, Appfelstaedt J, Llombart-Cussac A, Eremin J, Vinholes J, et al. Preoperative Treatment of Postmenopausal Breast Cancer Patients With Letrozole: A Randomized Double-Blind Multicenter Study. Ann Oncol Off J Eur Soc Med Oncol (2001) 12:1527-32. doi: 10.1023/ A:1013128213451

42. Ellis MJ, Ma C. Letrozole in the Neoadjuvant Setting: The P024 Trial. Breast Cancer Res Treat (2007) 105 Suppl:1, 33-43. doi: 10.1007/s10549-007-9701-x

43. Ellis M, Suman VJ, Hoog J, Lin L, Snider J, Prat A, et al. Randomized Phase II Neoadjuvant Comparison Between Letrozole, Anastrozole, and Exemestane for Postmenopausal Women With Estrogen Receptor-Rich Stage 2 to 3 Breast Cancer: Clinical and Biomarker Outcomes and Predictive Value of the Baseline PAM50-Based Intrinsic Subtype-ACOSOG Z1031. J Clin Oncol (2011) 29:2342-9. doi: 10.1200/JCO.2010.31.6950

44. Cataliotti L, Buzdar AU, Noguchi S, Bines J, Takatsuka Y, Petrakova K, et al. Comparison of Anastrozole Versus Tamoxifen as Preoperative Therapy in Postmenopausal Women With Hormone Receptor-Positive Breast Cancer:
The Pre-Operative "Arimidex" Compared to Tamoxifen (PROACT) Trial. Cancer (2006) 106:2095-103. doi: 10.1002/cncr.21872

45. Dowsett M, Smith IE, Ebbs SR, Dixon JM, Skene A, Griffith C, et al. ShortTerm Changes in Ki-67 During Neoadjuvant Treatment of Primary Breast Cancer With Anastrozole or Tamoxifen Alone or Combined Correlate With Recurrence-Free Survival. Clin Cancer Res An Off J Am Assoc Cancer Res (2005) 11:951s-8s.

46. Ellis MJ, Tao Y, Luo J, A'Hern R, Evans DB, Bhatnagar AS, et al. Outcome Prediction for Estrogen Receptor-Positive Breast Cancer Based on Postneoadjuvant Endocrine Therapy Tumor Characteristics. J Natl Cancer Inst (2008) 100:1380-8. doi: 10.1093/jnci/djn309

47. Cuzick J, Sestak I, Baum M, Buzdar A, Howell A, Dowsett M, et al. Effect of Anastrozole and Tamoxifen as Adjuvant Treatment for Early-Stage Breast Cancer: 10-Year Analysis of the ATAC Trial. Lancet Oncol (2010) 11:1135-41. doi: 10.1016/S1470-2045(10)70257-6

48. Howell A, Cuzick J, Baum M, Buzdar A, Dowsett M, Forbes JF, et al. Results of the ATAC (Arimidex, Tamoxifen, Alone or in Combination) Trial After Completion of 5 Years' Adjuvant Treatment for Breast Cancer. Lancet (London England) (2005) 365:60-2. doi: 10.1016/S0140-6736(04)17666-6

49. Gazet JC, Markopoulos C, Ford HT, Coombes RC, Bland JM, Dixon RC. Prospective Randomised Trial of Tamoxifen Versus Surgery in Elderly Patients With Breast Cancer. Lancet (London England) (1988) 1:679-81. doi: 10.1016/S0140-6736(88)91478-X

50. Goncalves R, Ma C, Luo J, Suman V, Ellis MJ. Use of Neoadjuvant Data to Design Adjuvant Endocrine Therapy Trials for Breast Cancer. Nat Rev Clin Oncol (2012) 9:223-9. doi: 10.1038/nrclinonc.2012.21

51. Ma CX, Ellis MJ. Neoadjuvant Endocrine Therapy for Locally Advanced Breast Cancer. Semin Oncol (2006) 33:650-6. doi: 10.1053/j.seminoncol. 2006.08.013

52. Goncalves R, Reinert T, Ellis MJ. Avoidance of Negative Results in Adjuvant Endocrine Therapy Trials for Estrogen Receptor-Positive Breast Cancer. J Clin Oncol (2017) 35:2718-9. doi: 10.1200/JCO.2017.73.0424

53. Ellis MJ, Suman VJ, Hoog J, Goncalves R, Sanati S, Creighton CJ, et al. Ki67 Proliferation Index as a Tool for Chemotherapy Decisions During and After Neoadjuvant Aromatase Inhibitor Treatment of Breast Cancer: Results From the American College of Surgeons Oncology Group Z1031 Trial (Alliance). J Clin Oncol (2017) 35:1061-9. doi: 10.1200/JCO.2016.69.4406

54. Miller WR, White S, Dixon JM, Murray J, Renshaw L, Anderson TJ. Proliferation, Steroid Receptors and Clinical/Pathological Response in Breast Cancer Treated With Letrozole. Br J Cancer (2006) 94:1051-6. doi: 10.1038/sj.bjc.6603001

55. Lerebours F, Pulido M, Fourme E, Debled M, Becette V, Bonnefoi H, et al. Predictive Factors of 5-Year Relapse-Free Survival in HR+/HER2- Breast Cancer Patients Treated With Neoadjuvant Endocrine Therapy: Pooled Analysis of Two Phase 2 Trials. Br J Cancer (2020) 122:759-65. doi: 10.1038/s41416-020-0733-x

56. Martí C, Sánchez-Méndez JI. Neoadjuvant Endocrine Therapy for Luminal Breast Cancer Treatment: A First-Choice Alternative in Times of Crisis Such as the COVID-19 Pandemic. Ecancermedicalscience (2020) 14:1027. doi: 10.3332/ecancer.2020.1027

57. Cavalcante FP, Novita GG, Millen EC, Zerwes FP, de Oliveira VM, Sousa ALL, et al. Management of Early Breast Cancer During the COVID-19 Pandemic in Brazil. Breast Cancer Res Treat (2020) 184:637-47. doi: 10.1007/s10549-02005877-y

58. Thompson CK, Lee MK, Baker JL, Attai DJ, DiNome ML. Taking a Second Look at Neoadjuvant Endocrine Therapy for the Treatment of Early Stage Estrogen Receptor Positive Breast Cancer During the COVID-19 Outbreak. Ann Surg (2020) 272:e96-7. doi: 10.1097/SLA.0000000000004027

59. Madigan LI, Dinh P, Graham JD. Neoadjuvant Endocrine Therapy in Locally Advanced Estrogen or Progesterone Receptor-Positive Breast Cancer: Determining the Optimal Endocrine Agent and Treatment Duration in Postmenopausal Women-a Literature Review and Proposed Guidelines. Breast Cancer Res BCR (2020) 22:77. doi: 10.1186/s13058-020-01314-6

60. Polley MY, Leung SC, McShane LM, Gao D, Hugh JC, Mastropasqua MG, et al. An International Ki67 Reproducibility Study. J Natl Cancer Inst (2013) 105:1897-906. doi: 10.1093/jnci/djt306

61. Leung SCY, Nielsen TO, Zabaglo LA, Arun I, Badve SS, Bane AL, et al. Analytical Validation of a Standardised Scoring Protocol for Ki67 
Immunohistochemistry on Breast Cancer Excision Whole Sections: An International Multicentre Collaboration. Histopathology (2019) 75:225-35. doi: $10.1111 /$ his. 13880

62. Rimm DL, Leung SCY, McShane LM, Bai Y, Bane AL, Bartlett JMS, et al. An International Multicenter Study to Evaluate Reproducibility of Automated Scoring for Assessment of Ki67 in Breast Cancer. Modern Pathol An Off J United States Can Acad Pathol Inc (2019) 32:59-69. doi: 10.1038/s41379-018-0109-4

63. Sledge GWJr. Put Some PEPI in Your Step: Ki67's Long Road to Respectability. J Clin Oncol (2017) 35:1031-2. doi: 10.1200/JCO.2016.71.2182

64. Chen R, Ye Y, Yang C, Peng Y, Zong B, Qu F, et al. Assessment of the Predictive Role of Pretreatment Ki-67 and Ki-67 Changes in Breast Cancer Patients Receiving Neoadjuvant Chemotherapy According to the Molecular Classification: A Retrospective Study of 1010 Patients. Breast Cancer Res Treat (2018) 170:35-43. doi: 10.1007/s10549-018-4730-1

65. Barchiesi G, Mazzotta M, Krasniqi E, Pizzuti L, Marinelli D, Capomolla E, et al. Neoadjuvant Endocrine Therapy in Breast Cancer: Current Knowledge and Future Perspectives. Int J Mol Sci (2020) 21(10):3528. doi: 10.3390/ijms21103528.

66. Cortazar P, Zhang L, Untch M, Mehta K, Costantino JP, Wolmark N, et al. Pathological Complete Response and Long-Term Clinical Benefit in Breast
Cancer: The CTNeoBC Pooled Analysis. Lancet (London England) (2014) 384:164-72. doi: 10.1016/S0140-6736(13)62422-8

Conflict of Interest: The authors declare that the research was conducted in the absence of any commercial or financial relationships that could be construed as a potential conflict of interest.

Publisher's Note: All claims expressed in this article are solely those of the authors and do not necessarily represent those of their affiliated organizations, or those of the publisher, the editors and the reviewers. Any product that may be evaluated in this article, or claim that may be made by its manufacturer, is not guaranteed or endorsed by the publisher.

Copyright (c) 2021 Zhang, Wang, Fan and Mao. This is an open-access article distributed under the terms of the Creative Commons Attribution License (CC BY). The use, distribution or reproduction in other forums is permitted, provided the original author(s) and the copyright owner(s) are credited and that the original publication in this journal is cited, in accordance with accepted academic practice. No use, distribution or reproduction is permitted which does not comply with these terms. 